\title{
Downhill varices-An unusual cause of hematemesis
}

\author{
Swati Kapoor ${ }^{1 *}$, Rajeev Upreti ${ }^{1}$, Abhishek Deo ${ }^{2}$ and Neeraj Awasthy ${ }^{3}$ \\ ${ }^{1}$ Department of Internal Medicine, Max Super Speciality Hospital, 1 Press Enclave Road, Saket, New Delhi, India \\ ${ }^{2}$ Department of Gastroenterology, Max Super Speciality Hospital, 1 Press Enclave Road, Saket, New Delhi, India \\ ${ }^{3}$ Pediatrics Cardiology, Max Super Speciality Hospital, 1 Press Enclave Road, Saket, New Delhi, India
}

\section{Introduction}

Varices in distal part of oesophagus are well known cause of upper gastrointestinal (GI) bleed. However proximal oesophageal varices, also known as "downhill" varices, are rare and account for only $0.1 \%$ of all cases of variceal haemorrhage $[1,2]$. They usually occur secondary to superior vena cava obstruction.

Here we report a case of 57-year-old male patient who underwent a renal transplant 3 months ago. He presented with an episode of haematemesis and was later diagnosed with as GI bleed secondary to downhill varices.

\section{Case}

A 57-year-old male who underwent renal transplant 3 months ago for chronic kidney disease (CKD) presented to emergency room (ER) after significant hematemesis. Prior to the transplant he was on haemodialysis via an internal jugular vein indwelling dialysis catheter which was removed in the peri-operative period. One month post surgery he developed facial swelling and was found to have thrombi in bilateral jugular veins and superior vena cava (SVC). He was started on anticoagulants (low molecular weight heparin and warfarin) and was monitored regularly.

On examination, patient was tachycardic (pulse - 110 per minute) and hypotensive (blood pressure - $90 / 60 \mathrm{mmHg}$ ) with rest of the examination being normal. Laboratory investigations revealed low haemoglobin $(\mathrm{Hb})$ of $7.3 \mathrm{gm} \%$, with an International Normalisation Ratio (INR) of 2.73. It was initially suspected that the bleeding was secondary to raised INR. He also passed melaena in ER.

Due to ongoing bleeding the anticoagulation was stopped, and 2 units of packed red blood cells and 4 units of fresh frozen plasma were transfused. An urgent upper GI endoscopy (UGIE) was done in Intensive Care Unit (ICU) which showed multiple large varices in the proximal oesophagus with tapering of varices distally. There was active bleeding seen from one of the varices at $30 \mathrm{~cm}$ from the incisors. Endoscopic band ligation was done during the same sitting with control of bleeding (Figures 1A-1C).

Over the next few hours the patient's tachycardia settled with normalising of blood pressure. The haemoglobin remained stable and there were no further episodes of haematemesis or melaena. The patient was also seen by a vascular surgeon and the existing left brachio-cephalic fistula, which was created for haemodialysis purpose, was ligated. Patient remained stable over the course of next 2 days and was discharged on Aspirin $75 \mathrm{mg}$ once daily with advice for follow up UGIE.
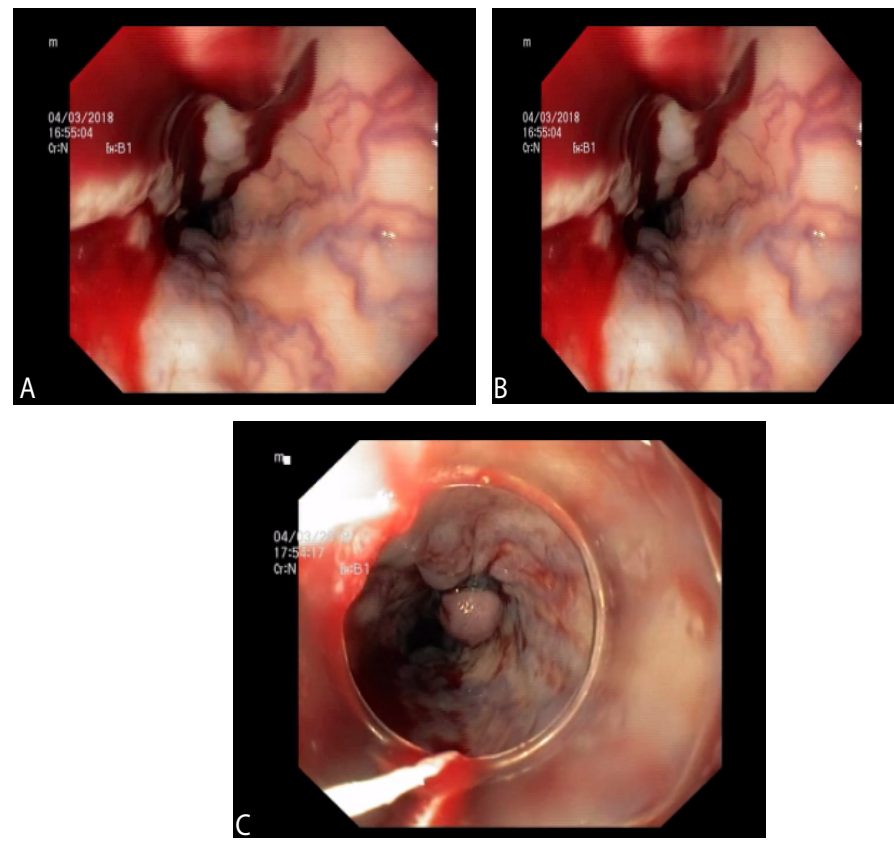

Figure 1: (A) and (B) show the large varices in upper part of oesophagus. Band ligation is shown in (C)

\section{Discussion}

Normal venous drainage of oesophagus is illustrated in the Figure 2. Any obstruction in superior vena cava or jugular veins will interfere with drainage of upper and middle oesophagus. Thus, eventually leading to formation of collaterals which may extend even distally depending on the level and duration of obstruction. If the obstruction is proximal to azygous vein, there will be formation of varices only in upper oesophagus owing to formation of mediastinal collaterals which drain into systemic circulation. However, if obstruction is below or at the level of azygous vein, varices extend distally as then collaterals drain via azygous, hemiazygos and portal veins [3-7] (Figure 2).

SVC obstruction is most commonly caused by compression from mediastinal malignancy, which account for $60 \%$ of cases as reported in literature [8]. However, in our case, the cause turned out to be completely

${ }^{\star}$ Correspondence to: Swati Kapoor, DNB Resident, Max Super-Speciality Hospital, 1 Press Enclave road, Saket, New Delhi: 110017, India, Tel: 08800861884; Fax: 911126510050; E-mail: swatikapoor3012@gmail.com

Received: April 02, 2018; Accepted: April 28, 2018; Published: April 30, 2018 


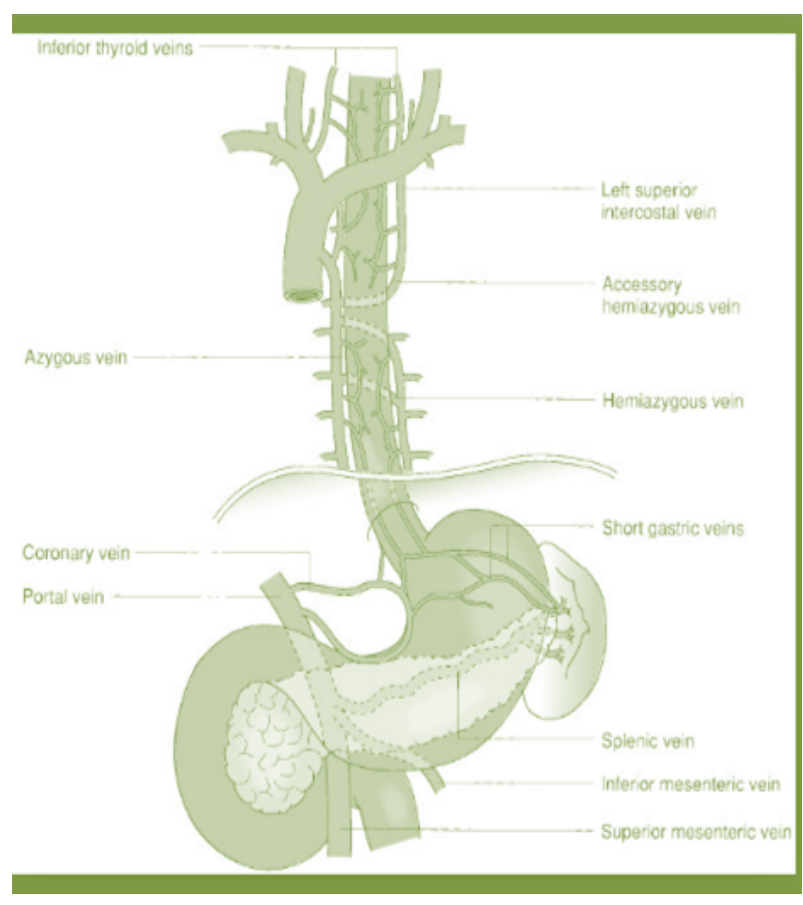

Figure 2: Venous drainage of oesophagus

benign which was not associated with any external compression. Our patient presented with superior vena cava thrombosis one month prior to episode of haematemesis. Interestingly, as per literature, in $30 \%$ of patients with SVC obstruction downhill varices are seen on screening UGIE [1].
Screening UGIE should be considered in patients who are on anticoagulants for SVC thrombus as there is additional risk of bleeding. Not much is known regarding pharmacological management of downhill varices unlike varices in distal part of oesophagus. Hence recanalizing SVC wherever possible must be carried out as a priority. This case report also testifies the usefulness of UGIE in not only diagnosis but also in management of variceal bleed in upper oesophagus.

\section{References}

1. Siegel Y, Schallert E, Kuker R (2015) Downhill esophageal varices: a prevalent complication of superior vena cava obstruction from benign and malignant causes. $J$ Comput Assist Tomogr 39: 149-152. [Crossref]

2. Areia M, Romãozinho JM, Ferreira M, Amaro P, Freitas D (2006) "Downhill" varices. A rare cause of esophageal hemorrhage. Rev Esp Enferm Dig 98: 359-361. [Crossref]

3. Otto DL, Kurtzman RS (1964) Esophageal varices in superior vena caval obstruction. Am J Roentgenol Radium Ther Nucl Med 92: 1000-1012. [Crossref]

4. Martorell F (1955) Esophageal varices due to superior caval hypertension. Angiologia 7: 49-53.

5. Johnson LS, Kinnear DG, Brown RA, Mulder DS (1978) "Downhill” esophageal varices. A rare cause of upper gastrointestinal bleeding. Arch Surg 113: 1463-1464.

6. Sorokin JJ, Levine SM, Moss EG, Biddle CM (1977) Downhill varices: report of a case 29 years after resection of a substernal thyroid gland. Gastroenterology 73: 345-348.

7. Hirose J, Takashima T, Suzuki M, Matsui O (1984) "Downhill" esophageal varices demonstrated by dynamic computed tomography. J Comput Assist Tomogr 8: 10071009.

8. Rice TW, Rodriguez RM, Light RW (2006) The superior vena cava syndrome: clinical characteristics and evolving etiology. Medicine (Baltimore) 85: 37-42. [Crossref]

Copyright: $(2018$ Kapoor S. This is an open-access article distributed under the terms of the Creative Commons Attribution License, which permits unrestricted use, distribution, and reproduction in any medium, provided the original author and source are credited. 